\title{
The impact of diabetes mellitus on acute kidney injury after coronary artery bypass grafting
}

\author{
Rui Wang ${ }^{*}$, Hang Zhang ${ }^{\dagger}$, Yifan Zhu, Wen Chen and Xin Chen ${ }^{*}$
}

\begin{abstract}
Background: Diabetes mellitus(DM) is an indicator affects postoperative mortality and morbidity after coronary artery bypass grafting (CABG). Acute kidney injury (AKI) is one of the frequent postoperative complications after CABG. This multi-centre register study designed to investigate the impact of DM on postoperative AKI in primary isolated CABG patients.
\end{abstract}

Methods: We included all patients $(n=4325)$ from Jiangsu Province CABG register who underwent primary isolated CABG from September 2017 to August 2019. The patients were divided into 3 groups: No-DM group $(n=3067)$, DMoral group (DM with oral hypoglycemic agents, $n=706$ ) and DM-insulin group (DM with insulin treatment, $n=552$ ). The development and severity of AKI were based on Acute Kidney Injury Network (AKIN) criteria.

Results: There were totally 338, 108 and 145 patients developed AKI in No-DM, DM-oral and DM-insulin group respectively. Comparing with No-DM group, DM-oral group had a higher rate of AKI ( $\left.X^{2}=10.071, p=0.002\right)$, DMinsulin group had a higher rate $\left(x^{2}=94.042, p<0.001\right)$ and severity of $\operatorname{AKI}\left(X^{2}=10.649, p=0.005\right)$. The adjusted odds ratio for AKI was 1.26 (95\% Cl 1.03-1.57) in DM-oral group and 3.92 (95\% Cl 3.27-5.16) in DM-insulin group, in comparison with No-DM group.

Conclusions: Independent of baseline renal function or cardiac function, DM was associated with an increased risk of AKI after CABG, especially in patients with insulin treatment, who also had a higher severity of AKI.

Keywords: Diabetes mellitus, Coronary artery bypass grafting, Acute kidney injury, Insulin

\section{Background}

Coronary artery bypass grafting (CABG) is recognized as one of the most effective procedures for the treatment of coronary artery atherosclerosis disease. Among patients undergoing CABG, diabetes mellitus (DM) accounted for $20-50 \%$ [1-3], and the proportion has increased steadily over the last 15 years $[4,5]$.

$\mathrm{DM}$ is a known risk factor for developing postoperative acute kidney injury (AKI) $[6,7]$. AKI is a sudden

\footnotetext{
*Correspondence: wr1582@163.com; stevecx@njmu.edu.cn

${ }^{+}$Rui Wang and Hang Zhang contributed equally to this work. Department of Cardiovascular Surgery, Nanjing First Hospital, Nanjing Medical University, Nanjing, 68 Changle Rd, Nanjing 210006, People's Republic of China
}

loss of kidney function defined by an acute increase in serum creatinine concentration and decrease in urinary output [8]. Up to $30 \%$ of patients with varying severity develop AKI after cardiac surgery, and approximately $2 \%$ require temporary dialysis [9]. Postoperative AKI is associated with increased short and long term morbidity and mortality $[10,11]$. Furthermore, DM is one of the major causes of nephropathy following CABG surgery [12]. However, there are limited studies which specifically investigated the different risk of AKI between patients with oral hypoglycemic treatment and insulin treatment after CABG. The purpose of this study was to investigate the association between DM and AKI following primary

(c) The Author(s). 2020 Open Access This article is licensed under a Creative Commons Attribution 4.0 International License, which permits use, sharing, adaptation, distribution and reproduction in any medium or format, as long as you give appropriate credit to the original author(s) and the source, provide a link to the Creative Commons licence, and indicate if changes were made. The images or other third party material in this article are included in the article's Creative Commons licence, unless indicated otherwise in a credit line to the material. If material is not included in the article's Creative Commons licence and your intended use is not permitted by statutory regulation or exceeds the permitted use, you will need to obtain permission directly from the copyright holder. To view a copy of this licence, visit http://creativecommons.org/licenses/by/4.0/ The Creative Commons Public Domain Dedication waiver (http://creativecommons.org/publicdomain/zero/1.0/) applies to the data made available in this article, unless otherwise stated in a credit line to the data. 
isolate $\mathrm{CABG}$, and to explore the effect of different treatment of DM on AKI.

\section{Methods \\ Definition of renal function}

The study was an observational province wide cohort study which included 13 cardiac centres in Jiangsu province. Data were collected routinely as part of a province CABG register, the register website is: http://221.226.21 8.114:10004/Multicenter. The Province-wide CABG Registry system was set in Nanjing First Hospital, the study was approved by the Ethics Committee of Nanjing First Hospital, and patient's identifiers were removed before analysis. DM was defined as the requirement for dietary modification, oral agents and/or insulin to lower blood glucose concentrations and was accepted as present based on the patient's history corroborated where possible by the medical records. The estimated glomerular filtration rate (eGFR) was calculated by the abbreviated Modification of Diet in Renal Disease equation: $186 \times(\text { serum creatinine/88.4 })^{-1.154} \times(\text { age })^{-0.203} \times$ (0.742 if female). AKI was defined and classified according to the criteria proposed by the Acute Kidney Injury Network (AKIN) as AKIN stage 1: increase creatinine $x$ 1.5 from baseline or increase of $>0.3 \mathrm{mg} / \mathrm{dL}$ within $48 \mathrm{~h}$; AKIN stage 2: increase creatinine $\times 2$ from baseline; and AKIN stage 3 : increase in creatinine $\times 3$ from baseline or creatinine $>4 \mathrm{mg} / \mathrm{dL}$ with an acute increase $>0.5 \mathrm{mg} / \mathrm{dL}$ within $48 \mathrm{~h}$ or new-onset of dialysis therapy [13].

\section{Study population}

A standard set of perioperative data was collected prospectively for patients undergoing primary isolated CABG who were enrolled in Jiangsu province CABG register between January 2017 and December 2019.

Patients undergoing a concomitant cardiac surgical procedure, reoperation, urgent or emergent operations, or with incomplete information were excluded. Totally there were 4325 cases up to the standard which were divided into 3 groups: No-DM group $(n=3067,70.9 \%))$, DM-oral group(DM with oral hypoglycemic agents, $n=$ $706,16.3 \%)$ and DM-insulin group(DM with insulin treatment, and with or without oral hypoglycemic agents, $n=552,12.8 \%$ ). On-pump CABG was performed via median sternotomy using a membrane oxygenator equipped with an arterial filter, cold blood antegrade cardioplegia under moderate systemic hypothermia (30 to $34^{\circ} \mathrm{C}$ ). The perfusion pressure during cardiopulmonary bypass $(\mathrm{CPB})$ was maintained within $60-70 \mathrm{mmHg}$. Off-pump CABG was performed by a suction stabilizer. Good exposure of lateral vessels might be got by using deep pericardial retraction sutures. Visualization was enhanced by using a blower device. Intra-coronary shunt was used routinely. Average of perioperative blood sugar level was tried to be controlled under $150 \mathrm{mg} / \mathrm{dl}$ by oral hypoglycemic agents and/or insulin treatment.

Twenty-one perioperative variables were collected including: age, gender, body mass index(BMI), eGFR, smoking, hypertension, DM and the type of treatment, hyperlipemia, chronic obstructive pulmonary disease(COPD), peripheral vascular disease(PVD), prior cerebro-vascular accident(CVA), myocardial infarction(MI) and percutaneous coronary intervention(PCI), left ventricular ejection fraction(LVEF), number of vessel disease, EuroSCOREII, number of distal anastomosis, the application of left internal mammary artery(LIMA) and radial artery, application of $\mathrm{CPB}$ or not and $\mathrm{CPB}$ time, the incidence and severity of AKI.

\section{Statistical analysis}

Data are represented as the mean \pm standard deviation unless otherwise indicated. Categorical variables are represented as frequency distributions and single percentages. Normally distributed continuous variables were compared using a Student t-test, non-normally distributed continuous variables using the Mann-Whitney $U$ test, and categorical variables were compared by $\chi^{2}$ test.

The multivariable analysis was adjusted for age, gender, BMI, eGFR, hypertension, hyperlipemia, COPD, PVD, prior CVA, MI and PCI, LVEF, number of vessel disease, EuroSCOREII, number and type of grafts, $\mathrm{CPB}$ and $\mathrm{CPB}$ time.

All statistical tests were two-sided. A $p$-value of less than 0.05 was considered significant. All statistical analysis were done with IBM SPSS Statistics 20.0 or STATA Data analysis and statistical software.

\section{Results}

Patient demographics and operative characteristics The baseline clinical characteristics of the study groups are given in Table 1. Comparing with No-DM group, DM-oral group had a higher percentage of female, higher BMI, higher incidence of PVD, prior MI and PCI, higher EuroSCOREII, higher CPB time, but a lower eGFR. Comparing with No-DM group, DM-insulin group had a higher age, higher percentage of female, higher BMI, higher incidence of hypertension, hyperlipemia and PVD, higher incidence of prior CVA, MI and PCI, higher number of vessel diseases and left main diseases, higher EuroSCOREII, a higher ratio of on-pump CABG and longer CPB time, but a lower eGFR and LVEF, and a lower application of LIMA (Table 1).

\section{Risk of AKI in relation to DM}

There were totally 338(11.0\%), 108(15.3\%) and 145(26.3\%) patients developed AKI postoperatively in No-DM, DM-oral and DM-insulin group respectively 
Table 1 Baseline and procedural characteristics in relation to type of treatment of DM

\begin{tabular}{|c|c|c|c|c|c|c|}
\hline Variable & $\begin{array}{l}\text { All cases } \\
(n=4325)\end{array}$ & $\begin{array}{l}\text { No-DM group } \\
(n=3067)\end{array}$ & $\begin{array}{l}\text { DM-oral group } \\
(n=706)\end{array}$ & $p$ & $\begin{array}{l}\text { DM-insulin group } \\
(n=552)\end{array}$ & $p$ \\
\hline Age, y & $64.1 \pm 8.4$ & $64.2 \pm 8.1$ & $64.8 \pm 7.6$ & 0.073 & $62.7 \pm 9.3$ & $<0.001$ \\
\hline Female gender & 793(18.3) & $506(16.5)$ & 148(21.0) & 0.005 & 139(25.2) & $<0.001$ \\
\hline $\mathrm{BMI}, \mathrm{kg} / \mathrm{m}^{2}$ & $26.7 \pm 4.9$ & $26.5 \pm 4.6$ & $27.3 \pm 5.2$ & $<0.001$ & $27.1 \pm 5.7$ & 0.002 \\
\hline $\mathrm{eGFR}\left(\mathrm{ml} / \mathrm{min} / 1.73 \mathrm{~m}^{2}\right)$ & $78.3 \pm 18.0$ & $80.3 \pm 17.8$ & $76.3 \pm 16.3$ & $<0.001$ & $69.5 \pm 19.4$ & $<0.001$ \\
\hline Hypertension & 2047(47.3) & 1414(46.1) & 343(48.6) & 0.234 & $290(52.5)$ & 0.005 \\
\hline Hyperlipemia & 1095(25.3) & $770(25.1)$ & $161(22.8)$ & 0.201 & 164(29.7) & 0.023 \\
\hline COPD & $312(7.2)$ & $221(7.2)$ & $53(7.5)$ & 0.781 & $38(6.9)$ & 0.787 \\
\hline Peripheral vascular disease & $369(8.5)$ & $230(7.5)$ & $71(10.1)$ & 0.024 & $68(12.3)$ & $<0.001$ \\
\hline \multicolumn{7}{|l|}{ Prior } \\
\hline CVA & 253(5.8) & $160(5.2)$ & $45(6.4)$ & 0.221 & $48(8.7)$ & $<0.001$ \\
\hline $\mathrm{Ml}$ & $697(16.1)$ & $463(15.1)$ & 130(18.4) & 0.029 & 104(18.8) & 0.026 \\
\hline $\mathrm{PCl}$ & 739(17.1) & $482(15.7)$ & 134(19.0) & 0.034 & $123(22.3)$ & $<0.001$ \\
\hline LVEF & & & & 0.867 & & 0.03 \\
\hline$>0.50$ & $3140(72.6)$ & 2248(73.3) & $513(72.7)$ & & $379(68.6)$ & \\
\hline $0.30-0.50$ & 1066(24.6) & $742(24.2)$ & $173(24.5)$ & & 151(27.4) & \\
\hline$<0.30$ & $119(2.8)$ & $77(2.5)$ & $20(2.8)$ & & $22(4.0)$ & \\
\hline No. of vessel disease & & & & 0.156 & & 0.02 \\
\hline 1 vessel & $222(5.1)$ & 181(5.9) & $29(4.1)$ & & $12(2.2)$ & \\
\hline 2 vessel & $473(10.9)$ & $328(10.7)$ & $81(11.5)$ & & 64(11.6) & \\
\hline 3 vessel & $3630(83.9)$ & 2558(83.4) & $596(84.4)$ & & $476(86.2)$ & \\
\hline Left main disease & 1073(24.8) & $721(23.5)$ & $179(25.4)$ & 0.299 & 173(31.3) & $<0.001$ \\
\hline EurOSCOREII & $2.1 \pm 0.8$ & $1.9 \pm 0.7$ & $2.4 \pm 0.9$ & $<0.001$ & $3.1 \pm 1.1$ & $<0.001$ \\
\hline \multicolumn{7}{|l|}{ Distal anastomosis } \\
\hline LIMA & 3954(91.4) & 2828(92.2) & 637(90.2) & 0.083 & 489(88.6) & 0.005 \\
\hline Radial artery & $151(3.5)$ & 107(3.5) & $26(3.7)$ & 0.801 & $18(3.3)$ & 0.787 \\
\hline On-pump & 1854(42.9) & $1270(41.4)$ & $315(44.6)$ & 0.119 & $269(48.7)$ & 0.001 \\
\hline CPB time(min) & $74.2 \pm 19.5$ & $71.5 \pm 18.9$ & $78.5 \pm 20.7$ & $<0.001$ & $83.5 \pm 23.2$ & $<0.001$ \\
\hline
\end{tabular}

No-DM group: non-DM; DM-oral group: DM with oral hypoglycemic agents; DM-insulin group: DM with insulin treatment, and with or without oral hypoglycemic agents. BMI body mass index, eGFR estimated glomerular filtration rate, COPD chronic obstructive pulmonary disease, CVA cerebro-vascular accident, MI myocardial infarction, $P C I$ percutaneous coronary intervention, $L V E F$ left ventricular ejection fraction, $L I M A$ left internal mammary artery, CPB cardiopulmonary bypass

(No-DM group vs. DM-oral group, $\mathrm{X}^{2}=10.071, p=$ 0.002; No-DM group vs. DM-insulin group, $\chi^{2}=94.042$, $\mathrm{p}<0.001)$. After adjustment for confounders, comparing with No-DM group, the risk of AKI in DM-insulin group was close to 4-fold (OR 3.92, 95\% CI 3.27-5.16); the risk of AKI in DM-oral group was 1.26, smaller but still significant (OR 1.26, 95\% CI, 1.03-1.57). (Table 2).

\section{Risk of AKI according to DM after stratified by} preoperative renal or cardiac function

When patients were stratified according to eGFR $(>60$, $\left.45-60,15-45 \mathrm{~mL} / \mathrm{min} / 1.73 \mathrm{~m}^{2}\right)$ or $\operatorname{LVEF}(>0.50,0.30$ $0.50,<0.30$ ), the associations between subtypes of different treatment of DM and AKI were similar for patients with reduced eGFR and normal eGFR, or with reduced LVEF and normal LVEF (Tables 3 and 4).

\section{Severity of AKI in relation to DM}

Comparing with No-DM group, DM-oral group had a higher rate of $\mathrm{AKI}\left(108\right.$ vs. $\left.338, \chi^{2}=10.071, p=0.002\right)$ but the severity of AKI was of no significance(AKIN stage1: 88 vs 294; AKIN stage2: 15 vs 32; AKIN stage3: 5 vs $\left.12, X^{2}=2.058, p=0.357\right)$. Comparing with No-DM group, DM-insulin group had a higher rate(145 vs. 338, $\left.\mathrm{X}^{2}=94.042, \mathrm{p}=0.002\right)$ and severity of AKI(AKIN stage1: 109 vs 294; AKIN stage2: 24 vs 32; AKIN stage3: 12 vs 12, $\left.\chi^{2}=10.649, p=0.005\right)$ (Table 5 and Fig. 1). 
Table 2 Odds ratios with 95\% Cls for AKI after CABG in 3 groups

\begin{tabular}{lllll}
\hline No. of patients & All & No-DM group & DM-oral group & DM-insulin group \\
& $\mathbf{4 3 2 5}$ & $\mathbf{3 0 6 7}$ & $\mathbf{7 0 6}$ & $\mathbf{5 5 2}$ \\
\hline No. of AKI(\%) & $591(13.7)$ & $338(11.0)$ & $108(15.3)$ & $145(26.3)$ \\
Risk of AKI & & OR $(95 \% \mathrm{Cl})$ & 2.88 \\
& & 1 & 1.46 & $2.31-3.59$ \\
(crude analysis) & & $1.15-1.84$ & 3.92 \\
Risk of AKI & & 1.26 & $3.27-5.16$ \\
(multivariable adjusted & ) & & $1.03-1.57$ & \\
\hline
\end{tabular}

AKI was defined as increase creatinine $\times 1.5$ from baseline or increase of $>0.3 \mathrm{mg} / \mathrm{dL}$ within $48 \mathrm{~h}$

${ }^{a}$ The final multivariable model included all variables in Table 1 except EuroSCOREII

\section{Discussion}

The principal findings of this province wide CABG register study can be summarized as follows: (1) Comparing with non-DM patients, DM patients were associated with an increased risk of AKI after CABG and were independent of baseline renal function or cardiac function. (2) Among DM patients, patients with insulin treatment were associated with an increased rate and severity of AKI compared with those with oral hypoglycemic agents treatment.

DM is the leading cause of chronic kidney disease(CKD), diabetic nephropathy and is increasing as a cause of morbility and mortality in the present era. Among all these complications, diabetic nephropathy has become the principal cause of end-stage renal failure and cardiovascular mortality $[14,15]$.

Table 3 Risk of AKI after CABG according to oral hypoglycemic and insulin treatment, stratified by preoperative renal function

\begin{tabular}{|c|c|c|c|c|}
\hline & All & No-DM group & DM-oral group & DM-insulin group \\
\hline \multicolumn{5}{|l|}{$\overline{\mathrm{eGFR}} \geq 60 \mathrm{~mL} / \mathrm{min} / 1.73 \mathrm{~m}^{2}$} \\
\hline No. of patients & 3456 & 2484 & 558 & 414 \\
\hline No. of AKI(\%) & $358(10.4)$ & 205(8.3) & $63(11.3)$ & $90(21.7)$ \\
\hline \multirow[t]{2}{*}{ Risk of AKI } & & OR $(95 \% \mathrm{Cl})$ & & \\
\hline & & 1 & 1.69 & 3.7 \\
\hline (crude analysis) & & & $1.25-2.28$ & $2.81-4.86$ \\
\hline Risk of AKI & & 1 & 1.2 & 4.35 \\
\hline (multivariable adjusted ${ }^{\mathrm{a}}$ ) & & & $0.89-1.66$ & $2.79-6.38$ \\
\hline \multicolumn{5}{|c|}{ eGFR $45-60 \mathrm{~mL} / \mathrm{min} / 1.73 \mathrm{~m}^{2}$} \\
\hline No. of patients & 644 & 461 & 89 & 94 \\
\hline No. of AKI(\%) & $150(23.3)$ & $96(20.8)$ & $23(25.8)$ & $31(32.8)$ \\
\hline \multirow[t]{2}{*}{ Risk of AKI } & & OR $(95 \% \mathrm{Cl})$ & & \\
\hline & & 1 & 1.33 & 1.87 \\
\hline (crude analysis) & & & $0.78-2.24$ & $1.15-3.04$ \\
\hline Risk of AKI & & 1 & 1.18 & 2.9 \\
\hline (multivariable adjusted $^{\mathrm{a}}$ ) & & & $0.64-2.07$ & $2.17-5.31$ \\
\hline \multicolumn{5}{|c|}{ eGFR $15-45 \mathrm{~mL} / \mathrm{min} / 1.73 \mathrm{~m}^{2}$} \\
\hline No. of patients & 225 & 122 & 59 & 44 \\
\hline No. of AKI(\%) & 83(36.9) & $37(30.3)$ & $22(37.3)$ & $24(54.5)$ \\
\hline \multirow[t]{2}{*}{ Risk of AKI } & & OR $(95 \% \mathrm{Cl})$ & & \\
\hline & & 1 & 1.37 & 2.75 \\
\hline (crude analysis) & & & $0.71-2.63$ & $1.36-5.60$ \\
\hline Risk of AKI & & 1 & 1.18 & 4.02 \\
\hline (multivariable adjusted $^{a}$ ) & & & $0.59-2.17$ & $2.44-6.59$ \\
\hline
\end{tabular}

AKI was defined as increase creatinine $\times 1.5$ from baseline or increase of $>0.3 \mathrm{mg} / \mathrm{dL}$ within $48 \mathrm{~h}$

${ }^{a}$ The final multivariable model included all variables in Table 1 except EuroSCOREII 
Table 4 Risk of AKI after CABG according to oral hypoglycemic and insulin treatment, stratified by preoperative cardiac function

\begin{tabular}{|c|c|c|c|c|}
\hline & All & No-DM group & DM-oral group & DM-insulin group \\
\hline \multicolumn{5}{|l|}{ LVEF $>0.50$} \\
\hline No. of patients & 3140 & 2248 & 513 & 379 \\
\hline No. of AKI(\%) & $350(11.1)$ & 203(9.0) & $63(12.3)$ & $84(22.2)$ \\
\hline \multirow[t]{2}{*}{ Risk of AKI } & & OR $(95 \% \mathrm{Cl})$ & & \\
\hline & & 1 & 1.41 & 2.87 \\
\hline (crude analysis) & & & $1.04-1.91$ & $2.16-3.80$ \\
\hline Risk of AKI & & 1 & 1.09 & 4.11 \\
\hline (multivariable adjusted ${ }^{a}$ ) & & & $0.79-1.31$ & $2.97-5.05$ \\
\hline \multicolumn{5}{|l|}{ LVEF $0.30-0.50$} \\
\hline No. of patients & 1066 & 742 & 173 & 151 \\
\hline No. of AKI(\%) & 201(18.9) & 114(15.4) & $38(22.0)$ & $49(32.5)$ \\
\hline \multirow[t]{2}{*}{ Risk of AKI } & & OR $(95 \% \mathrm{Cl})$ & & \\
\hline & & 1 & 1.55 & 2.65 \\
\hline (crude analysis) & & & $1.03-2.34$ & $1.78-3.93$ \\
\hline Risk of AKI & & 1 & 1.18 & 3.47 \\
\hline (multivariable adjusted*) & & & $0.67-1.84$ & $2.11-4.80$ \\
\hline \multicolumn{5}{|l|}{$\mathrm{LVEF}<0.30$} \\
\hline No. of patients & 119 & 77 & 20 & 22 \\
\hline No. of AKI(\%) & 40(33.6) & $21(27.3)$ & $7(35.0)$ & $12(54.5)$ \\
\hline \multirow[t]{2}{*}{ Risk of AKI } & & OR $(95 \% \mathrm{Cl})$ & & \\
\hline & & 1 & 1.44 & 3.2 \\
\hline (crude analysis) & & & $0.50-4.09$ & $1.20-8.51$ \\
\hline Risk of AKI & & 1 & 1.15 & 4.06 \\
\hline (multivariable adjusted $^{\mathrm{a}}$ ) & & & $0.34-3.57$ & $2.19-9.83$ \\
\hline
\end{tabular}

AKI was defined as increase creatinine $\times 1.5$ from baseline or increase of $>0.3 \mathrm{mg} / \mathrm{dL}$ within $48 \mathrm{~h}$

${ }^{a}$ The final multivariable model included all variables in Table 1 except EuroSCOREII

AKI is a frequent complication after cardiac surgery, which is known to have an adverse influence on the patients' outcomes, including progression to CKD, cardiovascular effects, sustained functional impairment and death. Minimal changes in postoperative creatinine can be associated with adverse effects. This diagnostic criteria for AKI is designed to facilitate the acquisition of a new concept in that small alterations in kidney function might contribute to adverse outcomes. In recent 10 years, over 80 cohort studies including more than 2 million participants have described relationships between

Table 5 Rate and severity of AKI after CABG in 3 groups

\begin{tabular}{rlll}
\hline & No-DM group & DM-oral group & DM-insulin group \\
\hline All AKI & 338 & 108 & 145 \\
Stage 1 & $294(87.0)$ & $88(81.5)$ & $109(75.2)$ \\
Stage 2 & $32(9.5)$ & $15(13.9)$ & $24(16.5)$ \\
Stage 3 & $12(3.5)$ & $5(4.6)$ & $12(8.3)$ \\
\hline
\end{tabular}

$\mathrm{AKI}$ and classification were defined according to Acute Kidney Injury Network (AKIN)
AKI and the risks of CKD, diabetic nephropathy and death [16]. However, a limited number of studies have focused on the difference between the type of treatment of DM patients undergoing CABG.

$\mathrm{DM}$ is speculated to aggravate AKI by the following complex mechanisms: (1) Hyperglycaemia can increase oxidative stress and amplify ischaemia-reperfusion injury [17]. (2) Celluar glucose overload induces mitochondrial dysfunction and kidney injury [18]. (3) Inflammation is an important factor for the development of kidney injury, and hyperglycaemia is reported to increase inflammatory cytokines such as interleukin-6, tumour necrosis factor- $\alpha$ and interleukin-18 [19]. (4) Endothelial dysfunction induced by hyperglycaemia leads to kidney injury [20]. In this study, DM patients undergoing CABG were associated with an increased risk of AKI compared with non-DM patients. The same result was obtained by Hertzberg D et al., they reported both type 1 and 2 DM were associated with an increased risk of AKI after CABG [21]. A Tekeli Kunt et al. reported the presence of metabolic syndrome (hyperglycemia, dyslipidemia, 


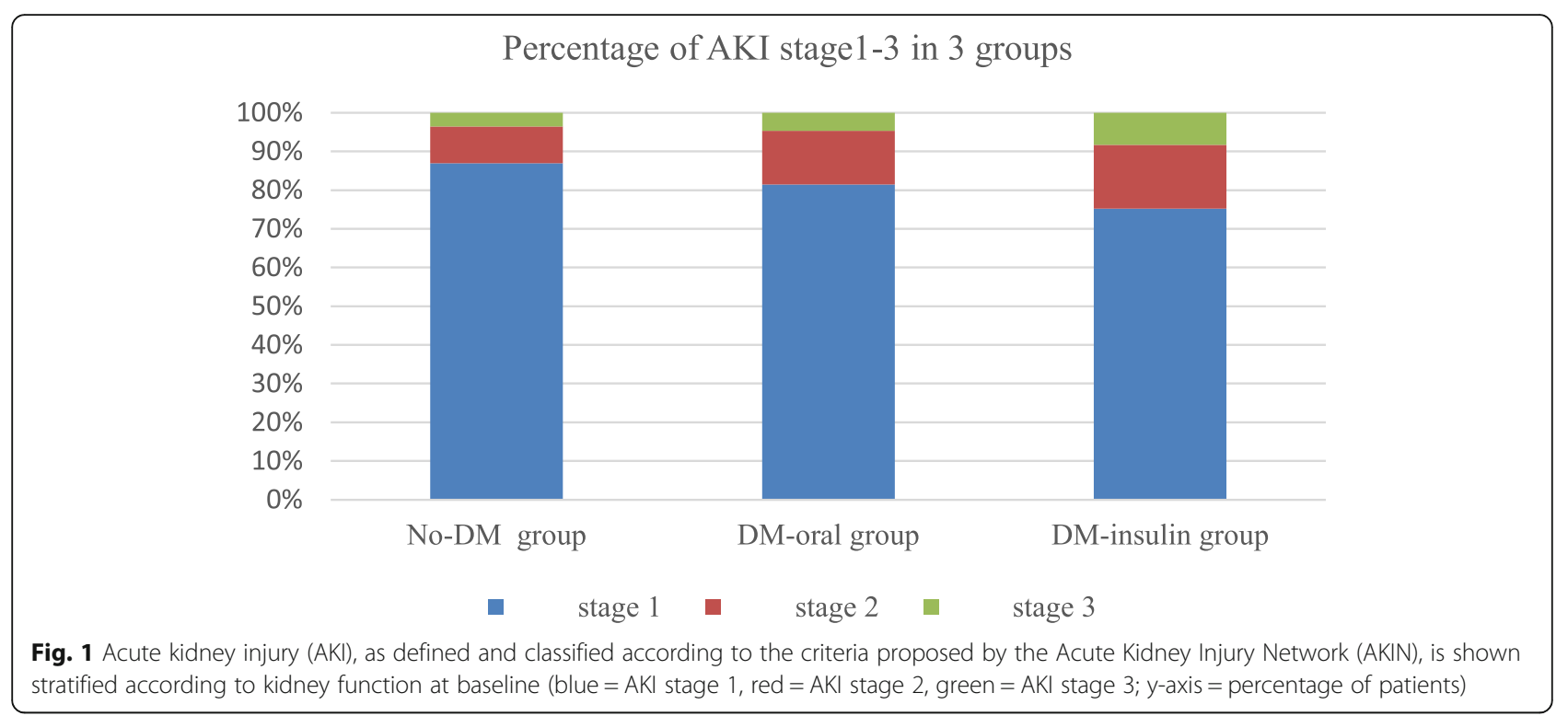

abdominal obesity, and hypertension) seemed to be associated with increased incidence of AKI after CABG [22]. Oezkur et al. concluded that chronic hyperglycemia defined on a single measurement of hemoglobin A1c $\geq 6.0 \%$ was also associated with the incidence of AKI after CABG. All of the above proved that DM was an independent risk factor for AKI after CABG [23].

Our subgroup analyses according to the type of DM treatment showed that when compared with those without DM, the risk of AKI were significantly higher in patients treated with oral hypoglycemic agents, and the risk and severity of AKI were both further significantly increased in patients treated with insulin. The conclusion from Hertzberg D et al. was in line with our study [21]. We speculated the reasons were as follows: (1) Hyperglycaemia, regardless of the presence of DM, is one of the major risk factors associated with poor prognosis including renal dysfunction, and more severe hyperglycaemia were more likely to be treated with insulin. (2) There must be some type 1 DM patients in DMinsulin group, despite we did not classify the type of $\mathrm{DM}$, and type $1 \mathrm{DM}$ was reported to be associated with a significant increased rate and severity of AKI compared with type $2 \mathrm{DM}$ [21].

Preoperative preexisting kidney disease and reduced left ventricular function are well known as important risk factors of postoperative AKI after CABG [24, 25]. For patients with preexisting kidney disease, it could be explained not only by an increased renal vulnerability but also by serum creatinine kinetics whereby an absolute increasement in serum creatinine levels by $0.3 \mathrm{mg} /$ $\mathrm{dL}$ is easier to reach when the baseline serum creatinine value is already enhanced. For patients with preexisting reduced left ventricular function, it could be explained not only by global hypoperfusion and renal malperfusion but also by cardiotonics and vasoconstrictors which might damage the renal function. So our study was further stratified by this two risk factors, which were measured in terms of eGFR and LVEF. After stratification, there was still a remakable increasement of postoperative AKI in DM patients compared with non-DM patients, in other words, the association between DM and the risk of AKI was similar in different eGFR or LVEF categories, although few studies have specifically studied this association. Meanwhile, this conclusion was also consistent with our subgroup analyses as mentioned before. Unfortunately, there are no pharmacologic agents known to reduce the risk of AKI or treat established AKI [26]. Therefore, DM patients undergoing CABG need to strengthen the perioperative glucose management and the follow-up of endocrinology.

\section{Limitations}

Firstly, a retrospective, non-randomized register study over a long period of time and with different surgeon's procedures on patients undergoing CABG is subjected to the effects of selection bias. Secondly, we only classified the DM according to the treatment instead of type(type1 and type2), and we were lack of details of glucose management and levels of hemoglobin A1c. Thirdly, it was impossible for us to stratify all risk factors, such as age, CPB, PVD and so on. Finally, We did not have information on the administration of angiotensin-converting enzyme inhibitors, angiotensin receptor blockers or aldosterone antagonists perioperatively, which could also be related to AKI. 


\section{Conclusions}

In summary, this analysis revealed that compared with non-DM patients, DM patients were associated with an increased risk of AKI after CABG irrespective of baseline renal function or cardiac function. The rate and severity of AKI were remarkable higher in DM patients with insulin treatment than those with oral hypoglycemic agents treatment.

\begin{abstract}
Abbreviations
DM: Diabetes mellitus; CABG: Coronary artery bypass grafting; AKI: Acute kidney injury; AKIN: Acute kidney injury network; eGFR: Estimated glomerular filtration rate; CPB: Cardiopulmonary bypass; BMI: Body mass index; COPD: Chronic obstructive pulmonary disease; PVD: Peripheral vascular disease; CVA: Cerebro-vascular accident; MI: Myocardial infarction; PCl: Percutaneous coronary intervention; LVEF: Left ventricular ejection fraction; LIMA: Left internal mammary artery; CKD: Chronic kidney disease
\end{abstract}

\section{Acknowledgements}

The authors are thankful to 12 collaborators of Jiangsu province CABG register study for making research in the registry possible. Collaborators are as following: 1 Affiliated Hospital of Nanjing Medical University, Nanjing; 2 Changzhou First People's Hospital, Changzhou; 3 The Affiliated Hospital of Xuzhou Medical University, Xuzhou; 4 Wuxi People's Hospital, Wuxi; 5 Affiliated Hospital of Nantong University, Nantong; 6 Zhongda Hospital, Nanjing; 7 Changzhou No.2 People's Hospital, Changzhou; 8 The First Affiliated Hospital of Soochow University, Soochow; 9 Xuzhou Central Hospital, Xuzhou; 10 General Hospital of Eastern Theater Command, Nanjing; 11 Huaian First People's Hospital, Huaian; 12 Nantong First People's Hospital, Nantong.

\section{Ethical approval and consent to participate}

This study was approved by The Ethics Committee of Nanjing First Hospital. All patients agreed that their stored material was enclosed and that their clinical data were anonymously used for statistical analysis.

\section{Authors' contributions}

RW and XC conceived of the study, and participated in its design and coordination and helped to draft the manuscript. RW and $\mathrm{HZ}$ participated in the design of the study and drafted the manuscript. YFZ and WC carried out the data collection and statistical analysis. All authors read and approved the final manuscript, and agreed for publication.

\section{Funding}

This work was supported by National Natural Science Foundation of China(No.81870193); Jiangsu Provincial Special Program of Medical Science(BE2017610); The Young Program of National Natural Science Foundation of China (No.81700415); The Project of Invigorating Health Care through Science, Technology and Education--Jiangsu Provincial Medical Youth Talent.

\section{Availability of data and materials}

All data and material are available by contacting wr1582@163.com

\section{Consent for publication}

Written informed consent was obtained from the patient before publication.

\section{Competing interests}

All of the authors declare that they have no competing interests.

Received: 30 June 2020 Accepted: 21 September 2020

Published online: 01 October 2020

\section{References}

1. Olsson D, Sartipy U, Braunschweig F, Holzmann MJ. Acute kidney injury following coronary artery bypass surgery and long-term risk of heart failure. Circ Heart Fail. 2013;6:83-90.
2. Garg AX, Devereaux PJ, Yusuf S, Cuerden MS, Parikh CR, Coca SG, et al. Kidney function after off-pump or on-pump coronary artery bypass graft surgery: a randomized clinical trial. J Am Med Assoc. 2014;311:2191-8.

3. Tolpin DA, Collard CD, Lee V-V, Virani SS, Allison PM, Elayda MA, et al. Subclinical changes in serum creatinine and mortality after coronary artery bypass grafting. J Thorac Cardiovasc Surg. 2012;143(3):682-8.e1. https://doi. org/10.1016/j.jtcvs.2011.09.044.

4. The Society for Cardiothoracic Surgery in Great Britain \& Ireland. Sixth National Cardiac Surgical database report: demonstrating quality, 2008.

5. Gallagher S, Kapur A, Lovell MJ, Yaqoob MM, et al. Impact of diabetes mellitus and renal insufficiency on 5-year mortality following coronary artery bypass graft surgery: a cohort study of 4869 UK patients. Eur J Cardiothorac Surg. 2014;45(6):1075-81.

6. Duran-Salgado MB, Rubio-Guerra AF. Diabetic nephropathy and inflammation. World J Diabetes. 2014:5:393-8.

7. Heyman SN, Rosenberger C, Rosen S, Khamaisi M. Why is diabetes mellitus a risk factor for contrast-induced nephropathy? Biomed Res Int. 2013;2013: 123589. https://doi.org/10.1155/2013/123589.

8. Kellum JA, Lameire N, KDIGO AKI Guideline Work Group. Diagnosis, evaluation, and management of acute kidney injury: a KDIGO summary (Part 1). Crit Care. 2013;17(1):204. https://doi.org/10.1186/cc11454.

9. Rosner MH, Okusa MD. Acute kidney injury associated with cardiac surgery. Clin J Am Soc Nephrol. 2006;1:19-32.

10. Ronco C, Bellomo R, Kellum JA. Acute kidney injury. Lancet. 2019; 394(10212):1949-64.

11. Coca SG, Yusuf B, Shlipak MG, Garg AX, Parikh CR. Long-term risk of mortality and other adverse outcomes after acute kidney injury: a systematic review and meta-analysis. Am J Kidney Dis. 2009;53:961-73.

12. Modine T, Zannis C, Salleron J, Provot F, Gourlay T, Duhamel A, et al. A prospective randomized study to evaluate the renal impact of surgical revascularization strategy in diabetic patients. Interact Cardiovasc Thorac Surg. 2010;11:406-10.

13. Kara I, Yildirim F, Kayacan E, Bilaloğlu B, Turkoglu M, Aygencel G. Importance of RIFLE (Risk, Injury, Failure, Loss, and End-Stage Renal Failure) and AKIN (Acute Kidney Injury Network) in Hemodialysis Initiation and Intensive Care Unit Mortality. Iran J Med Sci. 2017:42(4):397-403.

14. Gaballa M, Farag MK. Predictors of diabetic nephropathy. Eur J Med. 2013;8: 287-96. https://doi.org/10.2478/s11536-012-0055-3.

15. Maqbool M, Cooper ME, Jandeleit-Dahm KAM. Cardiovascular disease and diabetic kidney disease. Semin Nephrol. 2018;38(3):217-32. https://doi.org/ 10.1016/j.semnephrol.2018.02.003.

16. See EJ, Jayasinghe K, Glassford N, Bailey M, Johnson DW, Polkinghorne KR, et al. Long-term risk of adverse outcomes after acute kidney injury: a systematic review and meta-analysis of cohort studies using consensus definitions of exposure. Kidney Int. 2019;95(1):160-72. https://doi.org/10. 1016/j.kint.2018.08.036.

17. Hirose R, Xu F, Dang K, Liu T, Behrends M, Brakeman PR, et al. Transient hyperglycemia affects the extent of ischemia-reperfusion-induced renal injury in rats. Anesthesiology. 2008;108:402-14.

18. Vanhorebeek I, Gunst J, Ellger B, Boussemaere M, Lerut E, Debaveye Y, et al. Hyperglycemic kidney damage in an animal model of prolonged critical illness. Kidney Int. 2009;76:512-20.

19. Esposito K, Nappo F, Marfella R, Giugliano G, Giugliano F, Ciotola M et al. Inflammatory cytokine concentrations are acutely increased by hyperglycemia in humans: role of oxidative stress. Circulation. 2002;106: 2067-72.

20. Ellger B, Debaveye Y, Vanhorebeek I, Langouche L, Giulietti A, Van Etten E, et al. Survival benefits of intensive insulin therapy in critical illness: impact of maintaining normoglycemia versus glycemia-independent actions of insulin. Diabetes. 2006:55:1096-105.

21. Hertzberg D, Sartipy U, Holzmann MJ. Type 1 and type 2 diabetes mellitus and risk of acute kidney injury after coronary artery bypass grafting. Am Heart J. 2015;170(5):895-902. https://doi.org/10.1016/j.ahj. 2015.08.013.

22. Tekeli Kunt A, Parlar H, Findik O, Duzyol C, Baris O, Balci C. The Influence of Metabolic Syndrome on Acute Kidney Injury Occurrence after Coronary Artery Bypass Grafting. Heart Surg Forum. 2016;19(3):E099-103. Published 2016 May 18. https://doi.org/10.1532/hsf.1400.

23. Oezkur M, Wagner M, Weismann D, Krannich JH, Schimmer C, Riegler C, et al. Chronic hyperglycemia is associated with acute kidney injury in patients undergoing CABG surgery--a cohort study. BMC CardiovasC 
Disord. 2015;15:41. Published 2015 May 12. https://doi.org/10.1186/ s12872-015-0028-y.

24. Chen SW, Chang CH, Fan PC, Chen YC, Chu PH, Chen TH, et al. Comparison of contemporary preoperative risk models at predicting acute kidney injury after isolated coronary artery bypass grafting: a retrospective cohort study. BMJ Open. 2016;6(6):e010176. Published 2016 Jun 27. https://doi.org/10. 1136/bmjopen-2015-010176.

25. Thakar CV, Arrigain S, Worley S, Yared JP, Paganini EP. A clinical score to predict acute renal failure after cardiac surgery. J Am Soc Nephrol. 2005; 16(1):162-8. https://doi.org/10.1681/ASN.2004040331.

26. Thiele RH, Isbell JM, Rosner MH. AKI associated with cardiac surgery. Clin J Am Soc Nephrol. 2015;10:500-14.

\section{Publisher's Note}

Springer Nature remains neutral with regard to jurisdictional claims in published maps and institutional affiliations.

Ready to submit your research? Choose BMC and benefit from:

- fast, convenient online submission

- thorough peer review by experienced researchers in your field

- rapid publication on acceptance

- support for research data, including large and complex data types

- gold Open Access which fosters wider collaboration and increased citations

- maximum visibility for your research: over $100 \mathrm{M}$ website views per year

At BMC, research is always in progress.

Learn more biomedcentral.com/submissions 